\title{
Automatic Yarn Cut Detection in Power Loom using Iot
}

\author{
K. Prithivi, S. Thenmozhi, K. R. Vanathi, R. Gokulakrishnan, N. Praveen, M. \\ Sivachitra
}

\begin{abstract}
Textile trade has occupied second place next to agriculture. Due to the increase in population growth, textile trade in today's world is growing in plenty. A power loom is one of the main advances within weaving industrialization. It employs the country's more than thirty-five million people. Trade's main objective is to know its high-productivity power. The biggest downside which a textile trade is facing is that once the thread is cut the material gets broken. This results in the production of unnecessary cloth. The designed system is meant in such a simple way that it stops the device and avoids damage. This uses Raspberry pi 3 as the primary principal unit. The proposed system uses AC to DC Rectifier, A / D Converter and raspberry pi to signify automatic yarn cut detection in a loom. Using raspberry pi, this device mainly aims to detect the yarn cut in a loom. In this paper, the use of a single controller controls four power looms. Once the yarn cuts, the fault is detected, the supply may cut off immediately and then the fault is corrected.
\end{abstract}

Keywords: Raspberry pi, A/D converter, power loom, yarn..

\section{INTRODUCTION}

Textile trade has become the world's second-largest work-generating sector. The loom is an automated system that provides higher management of output tracking and takes corrective action. This provides greater control of quality and manufacturing. High productivity [7] is given by the continuous output of every single loom during milling. With its increasing growth and demand, textile trading faces many problems [8] that need to be improved. One of the approaches to solve those problems is the use of automation within the textile industry. Automation is often illustrated due to the method of reducing human help done within the System.

Revised Manuscript Received on February 05, 2020.

* Correspondence Author

K. Prithivi*, Assistant Professor, Department of EEE, Kongu Engineering College, perundurai Tamil Nadu, India.

E-mail: k.prthv@gmail.com

S. Thenmozhi, Department of EEE, Kongu Engineering College, perundurai, Tamil Nadu, India. E-mail: thenmozhi271999@gmail.com

K. R. Vanathi, Department of EEE, Kongu Engineering College, perundurai Tamil Nadu, India. E-mail: krvanathi1999@gmail.com

R. Gokulakrishnan, Department of EEE, Kongu Engineering College, perundurai Tamil Nadu, India. E-mail: gokulakrishnanra@gmail.com.

N. Praveen, Department of EEE, Kongu Engineering College, perundurai Tamil Nadu, India. E-mail: praveennallasivam@gmail.com

M. Sivachitra , Professor, Department of EEE, Kongu Engineering College, perundurai Tamil Nadu, India. E-mail: siva.chitra3@gmail.com

(C) The Authors. Published by Blue Eyes Intelligence Engineering and Sciences Publication (BEIESP). This is an open access article under the CC BY-NC-ND license (http://creativecommons.org/licenses/by-nc-nd/4.0/)
Machine-driven processes need less human intervention and less human development. A method-management or automation program is used to control a transaction mechanically. The Automation system method uses a network to interconnect sensors, controls, terminals for operators and actuators. The textile trade deals primarily with the preparation and produce of yarn, fabric and their distributions. The loom is one of the devices used in most small-scale industries for textile production. Loom may be a super-charged motorized loom with a line shaft and continuously monitored[2]. The majority of loom square elements measure warp beam, heddles, harnesses, shuttle, reed, and take roll. Various yarn processes such as shedding, picking, battening and take-up operations occur in various measures. Raise warp yarns to create a loop by adding the filling yarn borne by the shuttle as shedding. One shuttle crossing from one facet of the loom to the opposite is understood as the operation of choice. The birth of the yarn filling is known as a pounding. With each action, the recently made cloth will be wounded on an object which is known as a takeover operation. The most benefits of automation square measure are inflated outturn, inflated quality, improved hardiness and reduction of human loss.[4]

\section{EXISTING TECHNOLOGIES}

In the existing method there are many ways of technologies being used in power loom industry. But their performance is not widely used. Few technologies are as follows.

- Automation of plain weaving machine using PLC

- Power control and data log system design in loom industry using controller

- Power loom control using PIC18F4620

\section{A. Automation Of Plain Weaving Machine Using Plc}

The aim of automating plain weaving machines using PLC is to design a device that increases loom output and efficiency in different aspects without increasing costs. The PLC is used for managing, monitoring and regulating all computation and control required.

The main aspect of this is to adjust the basic power loom to act as an auto looms using the advantages of the system's Programmable Logic Controller (PLC). The process producing fabric is called weaving by interlacing warp and weft threads, and the method used for this is known as weaving machine. The proposed system is based on "plain power loom"[6] which is mainly mechanically controlled and has no electronic control and monitoring system at all.

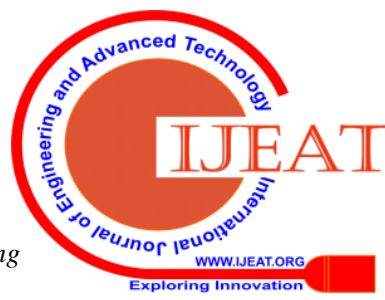


Because the number of the owner of plain power looms in India is very big, there are small industries and because of its very high cost, they cannot sell the automatic looms. The paper "automation in plain weaving machines using PLC" is intended to retrofit mechanical weaving machines into automatic weaving machines using a low-value PLC. Due to its power, usability, I/O interface, and reliable performance[5], PLCs are commonly used and favorite tools within the manufacturing automation industry.

\section{B. Power Control And Data Log System Design In Loom Industry Using Controller}

The proportion of output in the manufacturing industries depends on power and people. The person has a responsibility to control the waste of facilities in manufacturing industries once there is no raw input. The machinery of the loom requires manpower to permit the yarn. Once the work area unit has been delayed to allow the yarn to loom the machine, the loss of power supply can occur at a low motor load. In the design box, the microcontroller is connected to the PIC controller to dominate this power loss. The output pin of the PIC controller is connected to 8051, it offers loom standing. Once the loom has no yarn to run, this microcontroller ports multi-number of PIC controller's area unit are connected and shown in Figure.3.1. The purpose of the SD card is to connect to 8051, it takes data logs at low load once a motorturns off.Hence, the data logs are the operating

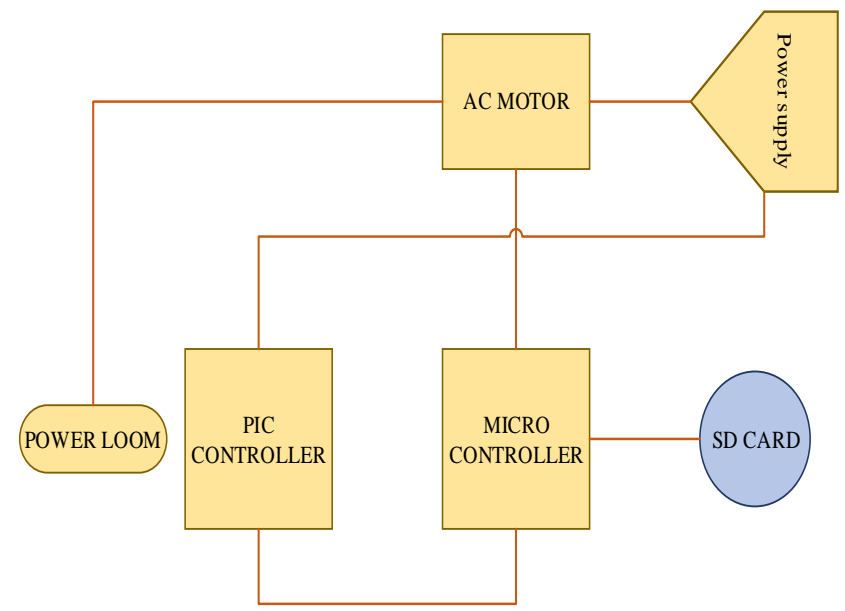

Figure.3.1.Block Diagram of power control and data log system

\section{Power loom control using pic18f4620}

After each (one after the other) movement of the shuttle across the fabric-making machine, the warp yarn layers and each pick of weft beat up into the cloth. Is cloth still to be woven this way in the next hundred years and after, or will some other process replace the past of weaving shows that the clever genius of man has continuously worked on the question of creating a woven fabric, and there are definite periods during which those ideas are reawakened and brought to the fore and seen as something new.

The industry does not have enough weavers and the hiring of new recruits is not enough. Wages in the cloth industry have changed a lot since the war and thus the wages of weaving (related to surgery) have been increased. controls the motor. Through microcontroller thirty two I/O stand of the microcontroller.

Manufacturers get a much better price for the fabric they make, and while we are supposed to be reaching a (prices are low and there are a lot of things for sale), those prices are likely to hold for some time.

The main consequences of these three reasons for increased interest are that it becomes very important for one (related to surgery) to pay attention to taking care of more machinery in order to maintain the production rate, it is very important that each worker produces more fabric because of the higher wages, and lastly, because cloth sells at a much better value. The major problem faced in the textile industry is that when the thread[3] gets to cut the fabric gets damaged. It leads to the production of defective clothing, which is the result of unnecessary growth.

The proposed system is designed in such a way that it stops the machine and prevents damage. The main controlling unit is PIC18F4620. The microcontroller communicates with the Led, Shuttle sensor, Warp sensor, and Relay. The shuttle sensor and warp sensor give thread condition status and are given as input to the microcontroller unit. Through the relay switching unit, the control unit shut down the machine. The status of the shuttle and warp sensor is shown on the LCD [12]screen, and the monitoring message is shown on the screen as well.

\section{PROPOSED SYSTEM}

In this paper, the device is designed in such a way that the device stops and prevents damage. This makes use of Raspberry pi 3 as the main controller. This paper provides automatic detection of yarn cut through A / D converters and raspberry pi 3 in power loom. This device mainly uses raspberry pi to detect yarn cut in power loom. A single controller is used to operate a maximum of four power looms. When the yarn cuts it is sensed by the controller, the supply will besuddenly cut off.The block diagram isshown in the figure 4.1 .

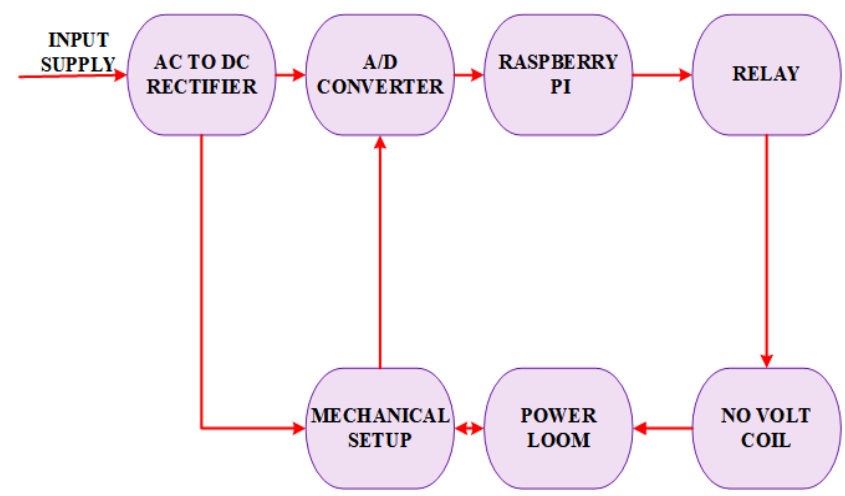

Figure.4.1.Block Diagram of the proposed power loom control

The proposed loom system consists of the main controller Raspberry pi. Here, Rectifier convertsanalog to a digital signal and is fed to the A/D Converter as input. The output of the raspberry pi is fed as a relay signal. No volt coil energizes[11] when the relay gets on. Power supply to the power looms are shut down at that time.

Published By:

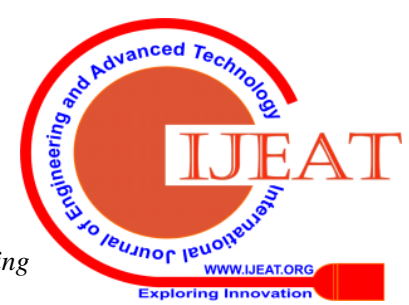




\section{HARDWARE DESCRIPTION}

The hardware setup consists of Raspberry pi, AC to DC Rectifier, Analog to digital converter, power loom, relay. The complete hardware setup is shown in the figure.5.1.

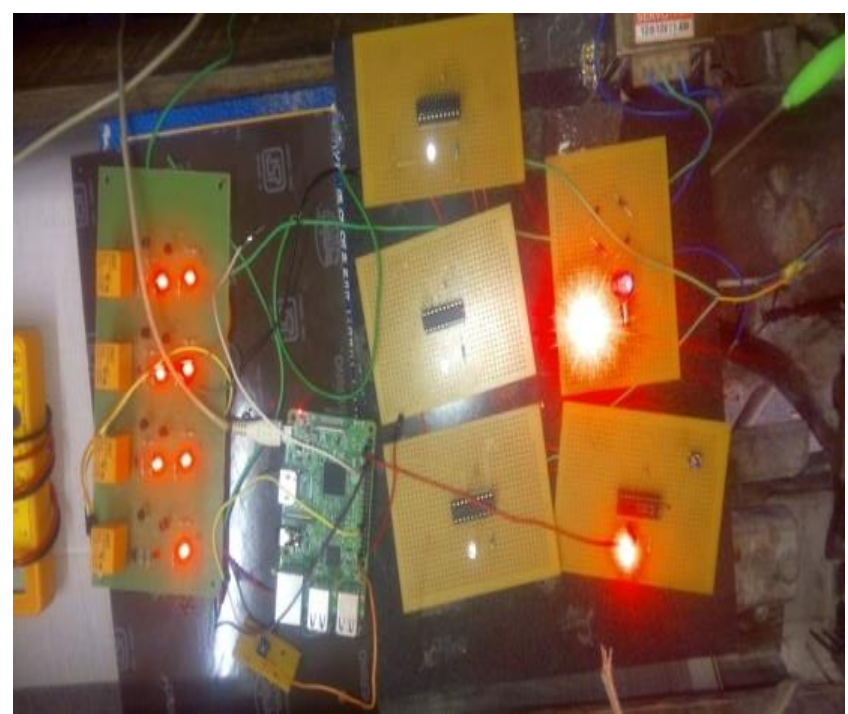

Figure.5.1.Hardware setup of the proposed system.

\section{A. Raspberry Pi}

The raspberry pi board features a program memory (RAM), processor and graphics module, CPU, GPU, LAN port, GPIO pins, Xbee connector[10], UART, instrumental power supply. And different interfaces for different exterior devices. It also needs mass storage, for which it tends to use associated SD storage card. Hardware specification of raspberry pi is shown within the figure.5.2.

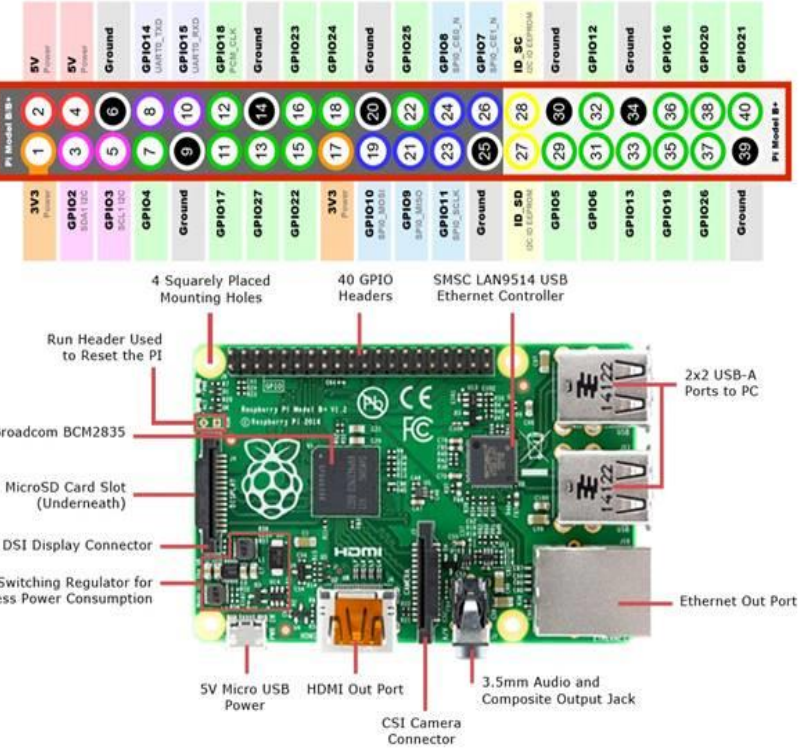

Figure.5.2.Hardware Specifications of Raspberry pi

\section{B.RELAY}

A relay is a device that is operated electrically. It consists of a set of terminals for one or more control signals and a collection of terminals for operational communication.

The transition could have all kinds of contacts in various contact ways, such as forming contacts, breaking contacts, or mixtures. Under figure 5.3 the relay Model is shown.
As $12 \mathrm{~V}$ is fed to the relay switch, at the time of fault detection, the relay coil is energized once it receives supply from the raspberry pi.

Relay circuit is shown in figure.5.4.

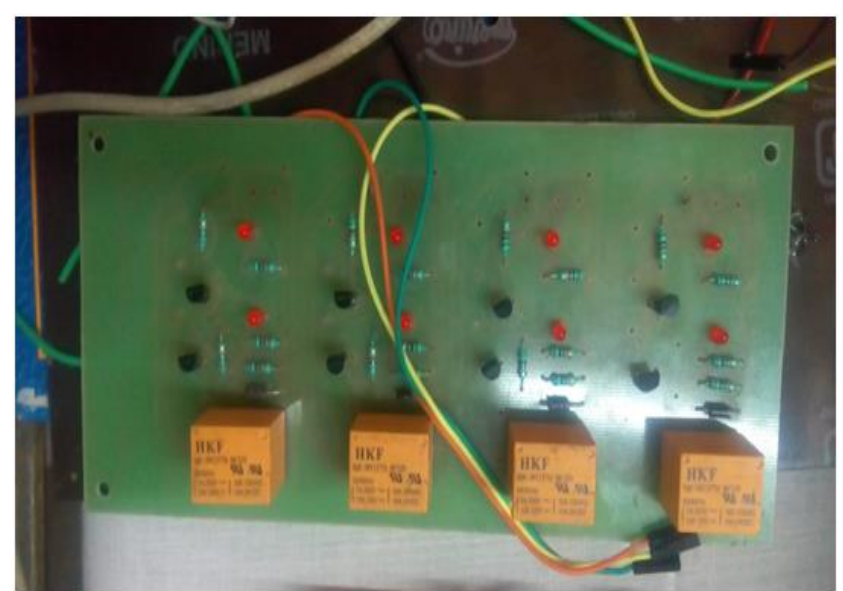

Figure.5.3.Relay Model

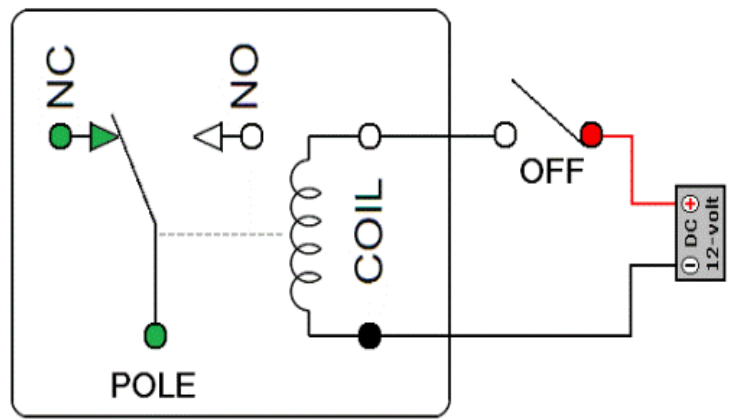

Figure.5.4 Relay Circuit

\section{Analog To Digital Converter}

To communicate with the digital processors such as Raspberry pi, this system needs an intermediate tool to transform the analog data into digital data.

When the fault occurred, the ADC converter receives a fault signal, where it transforms the analog signal to a digital signal. The ADC converter output is fed into the raspberry pi.The Analog and digital converter working is shown in the figure 5.5 .

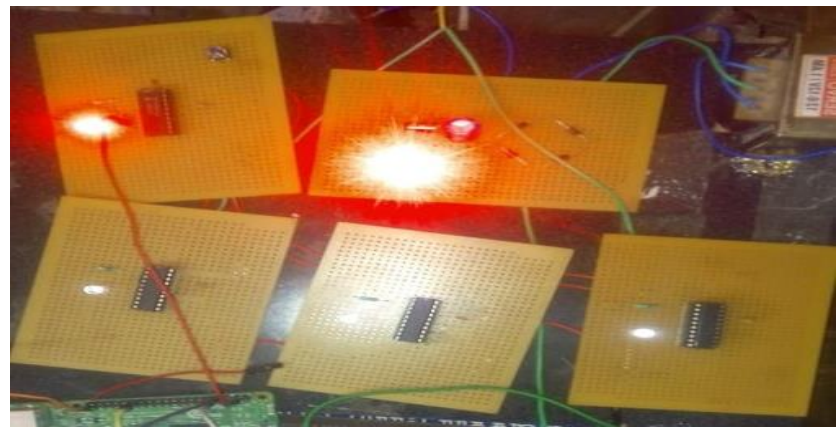

Figure.5.5.Analog to digital converter 


\section{Automatic Yarn Cut Detection in Power Loom using Iot}

\section{RESULT ANALYSIS AND DISCUSSION}

The system is in normal condition of processing. It can be applied in any field of industry such as textiles, power loom industries. This method obtains a finite result. It is for controlling the power loom functions automatically with the aid of Raspberry Pi as controller and also when yarn cuts automatically shut down the system during operating time and send a warning to the manager or employees and fault is corrected. In future, In addition to this, the sensed data from the loom will be shown to the user in the LCD and on the web server, the data can be accessed anywhere. The fineness of the material is measured. The entire system is easily controllable.

\section{CONCLUSION}

In this paper for the developing world, the Automatic Yarn Cut Detection within Power Loom has been introduced. Four power looms are operated using a single controller. The Raspberry Pi is used as a controller. The ADC converter senses the thread, and digital output sends to the raspberry pi when it slices. When the fault happens, the relay circuit is closed, and then the individual loom immediately stops and the fault is detected and fixed. The benefits of this method are, the entire system can be easily controlled, the configuration will be small in size and the problem can be easily rectified.

\section{REFERENCES}

1. Deepan.V, Divya.R, GowriManohari, Gowrishankar.S."Weaving Loom Monitoring And Control System Using Iot." In 2017 International Journal of Advanced Research in Science and Engineering,Volume: 06, Issue: 10

2. M. Saravanan, M. Jagadesh, V. Deepan, R. Divya, S. GowriManohari. "Smart Data Monitoring System for Power Loom Using IOT. ”In 2018 International Journal of Pure and Applied Mathematics, Volume 119 pp. 937-947.

3. Joarder, Kunal, and Daniel Raviv. "A novel method to calculate looming cue for threat of collision."In Proceedings of International Symposium on Computer Vision-ISCV, pp. 341-346.IEEE, 1995.

4. GurusamyPandian P.G., Sarvanasankar S., Ramasamy S.N., "Prevention of Fire Hazards and Control in South Indian Power Loom Industries using SHAPA Sensors." International Research Journal of Engineering and Technology , Volume: 02, Issue: 08 | Nov-2015

5. Dong, Deyi, and Zhenquan Shi. "The Loom Monitoring System Design with High Reliability and Easy Maintainability." In 2011 International Conference on Control, Automation and Systems Engineering (CASE), pp. 1-5.IEEE.

6. S. D. Gokhale , V. B. Kumbhar , P. P. Zirmite , S. P. Salgar "Automation of Plain Weaving Machine using PLC." In 2017 International Research Journal of Engineering and Technology, Volume: 04 Issue: 10

7. Chummar, Aby, and George Mathew SoniKuriakose. "Study on improving the production rate by rapier looms in textile industry." International Research Journal of Engineering and Technology,volume: 2,issue :7 (2013)

8. Shaik, Summaiya.R, and R.Dulange Satish."A study of factors affecting productivity of Power Loom Industries." International Journal of Engineering Research \& Technology (IJERT) 2, no. 12 (2013): 2278-0181.

9. Lei, W., Jiancheng, Y., Xiaoqin, H., Lei, L., Yan, L., \&Liangchao, C. (2009, December). The research on controlling method of loom warp tension. In 2009 Second International Symposium on Computational Intelligence and Design (Vol. 1, pp. 115-118). IEEE.

10. Nadaf, MrNiyaj S., Mrs JR Gangane, and Mr VB Kumbhar. "A Review on ZigBee based Industrial Automation using PLC." In 2015 International Journal of Emerging Technology in Computer Science \& Electronics (IJETCSE) Volume 14 , Issue 2.

11. Wagner, Arno, and Herbert Mueller. "Method for starting a power loom." U.S. Patent 6,307,340, issued October 23, 2001.

12. Vladimir, Gorbunov, Bobrikov Dmitriy, ThetNaing Win, and IonovEvgen. "The vision system in the weaving loom industry."
In 2017 IEEE Conference of Russian Young Researchers in Electrical and Electronic Engineering (EIConRus), pp. 669-671. IEEE, 2017.

\section{AUTHORS PROFILE}

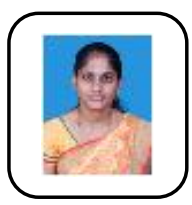

K. Prithivi, has completed her graduate degree in Electrical and Electronics Engineering in Kumaraguru College of Technology, Coimbatore, Tamil Nadu and master's degree in Power Electronics and Drives in Anna University Coimbatore, Tamil Nadu. Her current research work includes high efficiency power converters and power conditioning for fuel cell vehicles. Presently, she is working as an Assistant Professor in the Department of Electrical and Electronics Engineering, Kongu Engineering College, Perundurai, Tamil Nadu. She has 10 years of academic experience. She has presented papers in National and International Journals and Conferences. Her research area includes: DC-DC converters, Fuel cell hybrid electric vehicle, Power Conditioning unit and Computational Intelligent Techniques.

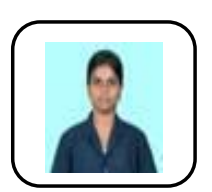

S. Thenmozhi, is the student of Kongu Engineering College, Perundurai, Erode, Tamil Nadu. She is currently pursuing her UG degree in EEE. She is currently doing her under graduate project in the area of electronics. She is a Student member of IEI.

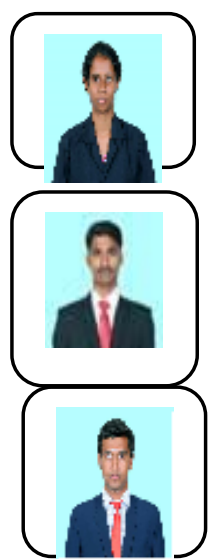

K. R. Vanathi, is the student of Kongu Engineering College, Perundurai, Erode, Tamil Nadu. She is currently pursuing his UG degree in EEE. She is currently doing her under graduate project in the area of electronics. She is a student member of National Service Scheme(NSS).

R. Gokulakrishnan, is the student of Kongu Engineering College, Perundurai, Erode, Tamil Nadu. He is Currently pursuing his UG degree in EEE. He is currently doing his under graduate project in the area of electronics.

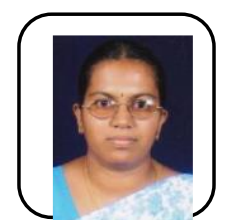

N. Praveen, is the student of Kongu Engineering College, Perundurai, Erode, Tamil Nadu. He is Currently pursuing his UG degree in EEE. He is currently doing his under graduate project in the area of electronics.

M. Sivachitra, received B.E Degree in Electrical and Electronics Engineering from Bharathiyar University in The year 2000 and M.E(Applied Electronics) from Anna University, Chennai in the year2006 and $\mathrm{PhD}$ in 2016 from Anna University, Chennai. She is working in the area of complex valued neural networks. She has a total teaching experience of 19years.A present she is working as a Professor in Kongu Engineering College, Autonomous institution affiliated to Anna University Chennai. She has attended International conferences and published papers in International journals . .She has conducted workshops

And seminars in her research area.

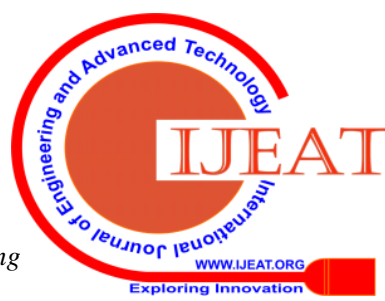

